09,03

\title{
Изменение структуры и люминесцентных свойств пленок ZnSe и ZnCdSe при облучении электронным пучком
}

\author{
() В.А. Кравец, Е.В. Дементьева, А.А. Ситникова, И.В. Седова, М.В. Заморянская \\ Физико-технический институт им. А.Ф. Иофрфе РАН, \\ Санкт-Петербург, Россия \\ E-mail: vladislav2033@yandex.ru
}

Поступила в Редакцию 7 октября 2021 г.

В окончательной редакции 7 октября 2021 г.

Принята к публикации 10 октября 2021 г.

Исследовались слои $\mathrm{ZnSe}$ и $\mathrm{ZnCd}_{x} \mathrm{Se}(x \sim 0.32-0.35)$, выращенные на подложках $\mathrm{GaAs}(001)$ методом молекулярно-пучковой эпитаксии. Изучалось влияние электронного пучка на изменения кристаллической структуры изучаемых образцов и люминесцентные свойства. Исследования проводились методами катодолюминесценции, просвечивающей электронной микроскопии и методом рентгеноспектрального микроанализа.

Установлено, что в результате облучения образцов в просвечивающем электронном микроскопе происходит отжиг дефектов упаковки, сопровождаемый образованием преципитатов ZnO с гексагональной кристаллической структурой. Облучение образцов в катодолюминесцентной установке приводит к уменьшению интенсивности катодолюминесценции исследуемых слоев $\mathrm{ZnSe}$ и $\mathrm{ZnCd}_{x} \mathrm{Se}$ из-за радиационностимулированных процессов деградации.

Ключевые слова: точечные дефекты, облучение электронным пучком, катодолюминесценция, структурные изменения.

DOI: 10.21883/FTT.2022.02.51934.219

\section{1. Введение}

Полупроводниковые лазеры на основе $\mathrm{ZnSe}$, излучающие в сине-зеленом спектральном диапазоне востребованы во многих областях науки и техники - телевидении, освещении, оптоэлектронике, лазерных навигационных системах, качественной цветной печати и др. [1].

Главная проблема получения инжекционного синезеленого лазера связана с трудностями легирования $p$-типа широкозонных полупроводников $\mathrm{A}^{2} \mathrm{~B}^{6}$ из-за термодинамической нестабильности азотного акцептора [2], которая приводит к быстрой деградации лазерного диода и, соответственно, малому сроку службы прибора.

В связи с этим, повышенное внимание уделялось разработке альтернативных путей получения лазерной генерации, не требующих $p-n$-перехода и омических контактов, а именно созданию сине-зеленых полупроводниковых лазерных конвертеров $\left.\mathrm{A}^{2} \mathrm{~B}^{6} / \mathrm{A}^{3} \mathrm{~N}[3,4]\right)$ и полупроводниковых лазеров $\mathrm{A}^{2} \mathrm{~B}^{6} \mathrm{c}$ электронно-лучевой накачкой (ПЛЭН) [5]. В последних исследованиях значения рабочей энергии электронов, требуемой для их работы при комнатной температуре были снижены до 4-10 keV, была получена генерация при рекордно низких значениях пороговой плотности тока пучка электронов - около $0.5 \mathrm{~A} / \mathrm{cm}^{2}$ [6], а использование лазерной сборки позволило получить импульсы излучения мощностью более $600 \mathrm{~W}$ [7]. Была продемонстрирована возможность работы ПЛЭН в течение нескольких часов без уменьшения выходной мощности, и показано, что, по всей видимости, именно количество дефектов в исходной гетероструктуре является фактором, определяющим срок службы лазеров [8]. В связи с этим исследования результатов воздействия электронного пучка на отдельные слои $\mathrm{ZnSe}$ и $\mathrm{ZnCdSe}$, являющиеся базовыми в лазерных гетероструктурах, является актуальным.

В настоящей работе представлены результаты исследования процесса деградации слоев $\mathrm{ZnSe}$ и $\mathrm{ZnCd}_{x} \mathrm{Se}$ $(x \sim 0.32-0.35)$ толщиной $\sim 1 \mathrm{mkm}$ при облучении электронным пучком. Дана оценка влияния процесса деградации на люминесцентные свойства материала.

\section{2. Образцы и методы исследования}

Слои ZnSe (№ 688) и ZnCdSe (№ 707 и № 713) кубической структуры типа цинковой обманки (сфалерита), были получены методом молекулярно-пучковой эпитаксии (МПЭ) на подложках GaAs (001) с использованием буферного слоя GaAs в двухкамерной установке МПЭ (SemiTeq, Россия). Пленки исследовались методами локальной катодолюминесценции (КЛ), просвечивающей электронной микроскопии (ПЭМ) и рентгеноспектрального микроанализа (РСМА).

Структурное совершенство образцов исследовалось методом ПЭМ в геометрии поперечного сечения в режиме светлого поля на электронных микроскопах JEM-2100F (Jeol) и EM 420 (Philips). Были подготовлены образцы в геометрии поперечного сечения. Образцы были утонены при травлении ионами $\mathrm{Ar}^{+}$. Далее исследование образцов состояло из 3 этапов.

1. Методом ПЭМ в геометрии поперечного сечения были получены изображения Аисходных образцов при 
малых токах $(I=1 \mathrm{nA})$ электронного пучка. Режим пучка подбирался таким образом, чтобы избежать видимых изменений свойств исследуемого слоя.

2. Затем ранее исследованные области дополнительно облучались в ПЭМ электронным пучком (ток пучка $I=25-100 \mathrm{nA}$ ), при котором происходили видимые оператору процессы деградации образца (появление включений, изменение количества дефектов упаковки).

Облучения образцов № 688 и 713 проводилось в микроскопе JEM-2100F (Jeol) при следующих параметрах электронного пучка: ток $-100 \mathrm{nA}$, энергия $-100 \mathrm{keV}$, радиус пучка $-1 \mathrm{mkm}$. Облучение образца № 707 проводилось в микроскопе EM 420 (Philips), режим облучения: энергия электронов $-200 \mathrm{keV}$, ток $-25 \mathrm{nA}$, радиус пучка $-1 \mathrm{mkm}$.

3. Далее были получены ПЭМ-изображения облученных областей при малых токах электронного пучка $(I=1 \mathrm{nA})$.

Катодолюминесцентные исследования и рентгеноспектральный микроанализ образцов проводились на рентгеноспектральном микроанализаторе CAMEВАХ производства фирмы Сатеса, оснащенном четырьмя рентгеновскими спектрометрами и оптическими спектрометрами оригинальной конструкции [9]. Данный прибор позволяет получать спектры КЛ и измерять состав материала в области размером $\sim 1 \mathrm{mkm}$.

Исследования свойств образцов методом КЛ проводились как при комнатной температуре $(300 \mathrm{~K})$, так и при температуре жидкого азота $(77 \mathrm{~K})$. при следующих характеристиках электронного пучка: энергия электронов $-10 \mathrm{keV}$, ток электронного пучка $-100 \mathrm{nA}$, радиус электронного пучка $-2 \mathrm{mkm}$. Спектры КЛ облучаемой области регистрировались с интервалами $4-5 \mathrm{~min}$ при общей длительности облучения образца $20 \mathrm{~min}$, при этом регистрация спектра составляла $2 \mathrm{~min}$.

Измерения состава как исходных образцов, так и образцов после облучения электронным пучком проводились методом РСMА при энергии электронов $10 \mathrm{keV}$, поглощенном токе $15 \mathrm{nA}$ и радиусе электронного пучка $2 \mathrm{mkm}$. В качестве эталонов использовались пленки $\mathrm{ZnSe}$ и CdSe. Глубина проникновения электронного пучка для структур $\mathrm{ZnSe} / \mathrm{GaAs}$ и $\mathrm{ZnCdSe} / \mathrm{GaAs}$ при энергии электронов $10 \mathrm{keV}$ не превышала толщину исследуемых пленок.

\section{3. Эксперементальные результаты и обсуждения}

\section{1. Исследование исходных пленок}

На рис. 1 представлены спектры КЛ образцов № 688, 713 и 707 полученные при комнатной температуре в первые две минуты облучения электронным пучком. Следует отметить, что за данный интервал времени существенных изменений спектров КЛ отмечено не было.

В спектрах КЛ (рис. 1) наблюдаются полосы собственной краевой люминесценции пленок (далее „краевые

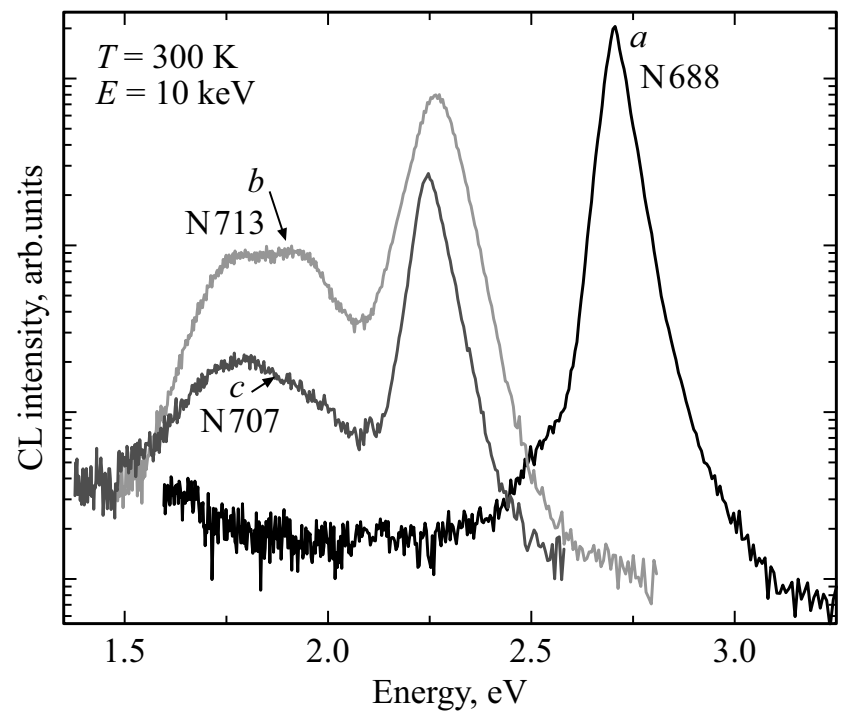

Рис. 1. Спектры КЛ-образцов, полученные в первые две минуты облучения электронным пучком в полулогарифмическом масштабе: $a$ ) ZnSe № 688, b) ZnCdSe № 713 и с) ZnCdSe № 707.

полосы“") с максимумами в области $2.7 \mathrm{eV}$ (№688), $2.29 \mathrm{eV}$ (№ 713) и $2.26 \mathrm{eV}$ (№ 707). Наряду с ними в образцах № 713 и 707 наблюдаются полосы, связанные с люминесценцией точечных дефектов (далее „широкие полосы“) в области от 1.5 до $2 \mathrm{eV}$. Положение максимума данной полосы в КЛ-спектре образца № 707 наблюдалось в области $1.83 \mathrm{eV}$. У образца № 713 широкая полоса представляла собой дуплет с двумя максимумами 1.78 и $1.91 \mathrm{eV}$, что значительно отличается от спектра образца № 707. В литературе данные полосы связывают с комплексами точечных дефектов с участием вакансий [10], что соответствует переходу донор двухзарядная вакансия цинка $\left(\mathrm{D}-\mathrm{V}_{\mathrm{Zn}-2}\right)$, который описан в работе [11].

На рис. $2, a, b$, с представлены светлопольные изображения исходных образцов, полученные методом ПЭМ в геометрии поперечного сечения. С помощью этих изображений была проведена оценка концентрации наблюдаемых дефектов упаковки и определена толщина исследуемых пленок. Результаты проведенных исследований представлены в табл. 1.

ПЭМ-изображение образца №688 представлено на рис. $2, a$. Концентрация наблюдаемых дефектов упаковки менее $1 \cdot 10^{7} \mathrm{~cm}^{-2}$. При этом наблюдается массив темных включений, контраст которых характерен для мелких преципитатов, которые не отражаются на картине электронной дифракции рис. $3, a$. На картине микродифракции отчетливо видны дифракционные рефлексы, соответствующие только соединению $\mathrm{ZnSe}$.

На изображении в геометрии поперечного сечения образцов № 713 и 707 отчетливо видны дефекты упаковки (рис. 2,b,c), зарождающиеся на гетеровалентном интерфейсе $\mathrm{ZnSe} / \mathrm{GaAs}$. Концентрация наблюдаемых дефектов упаковки $\sim 2 \cdot 10^{8}$ и $\sim 4 \cdot 10^{8} \mathrm{~cm}^{-2}$ соответ- 
Таблица 1. Результаты исследования пленов методами РСМА, КЛ и ПЭМ

\begin{tabular}{c|c|c|c|c|c}
\hline Образец & $\begin{array}{c}\text { Толщины } \\
\text { слоев, } \mathrm{nm}\end{array}$ & $\begin{array}{c}\text { Концентрация } \\
\text { наблюдаемых } \\
\text { дефектов } \\
\text { упаковки, } \mathrm{cm}^{-2}\end{array}$ & $\begin{array}{c}\text { Состав пленок, } \\
\text { полученный } \\
\text { методом } \\
\text { РСMA }\end{array}$ & $\begin{array}{c}\text { Положение } \\
\text { максимума } \\
\text { краевой полосы } \\
(300 \mathrm{~K}), \mathrm{eV}\end{array}$ & $\begin{array}{c}\text { Положение } \\
\text { максимума полосы, } \\
\text { связанной с точечными } \\
\text { дефектами }(300 \mathrm{~K}), \mathrm{eV}\end{array}$ \\
\hline № 688 & 870 & $<1 \cdot 10^{7}$ & $\mathrm{ZnSe}$ & 2.7 & - \\
\hline № 713 & 890 & $\sim 2 \cdot 10^{8}$ & $\mathrm{Zn}_{0.68} \mathrm{Cd}_{0.32} \mathrm{Se}$ & 2.29 & 1.78 \\
\hline № 707 & 600 & $\sim 4 \cdot 10^{8}$ & $\mathrm{Zn}_{0.65} \mathrm{Cd}_{0.35} \mathrm{Se}$ & 2.26 & 1.91 \\
\hline
\end{tabular}

ственно. Состав слоев ZnCdSe определялся методом PCMA в 5-10 точках, выбранных случайным образом. Исследования показали, что пленки однородны по составу.

\section{2. Облучение электронным пучком с энергией 100 и $200 \mathrm{keV}$}

На рис. 2 представлены полученные в одной и той же области светлопольные ПЭМ-изображения образцов до облучения электронным пучком (рис. 2, $a, b, c)$ и после облучения (рис. 2, $d, e)$. электронным пучком с энергией $100 \mathrm{keV}$ (№ 688, 713) и $200 \mathrm{keV}$ (№ 707).
После облучения образца №688 на ПЭМ-изображении появляются более крупные включения (рис. 2,d), чем те, которые были видны до облучения (рис. 2,a). При сравнении изображения исходного (рис. $2, b, c)$ и облученного (рис. 2,e,f) образцов № 713 и 707 видно, что после облучения контраст, связанный с дефектами упаковки, исчезает, и появляются темные включения - преципитаты. По данным микродифракции преципитаты, возникающие во всех образцах после облучения, являются гексагональными включениями $\mathrm{ZnO}$ (рис. $3, b)$.

Так же после облучения во всех образцах появились светлые включения с контрастом характерным для пор. $a$

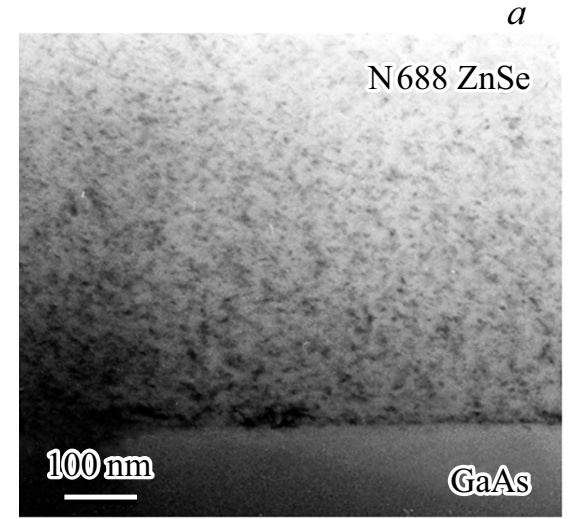

$d$

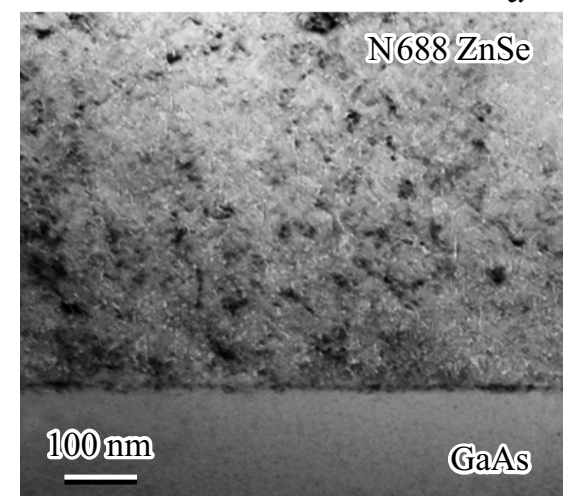

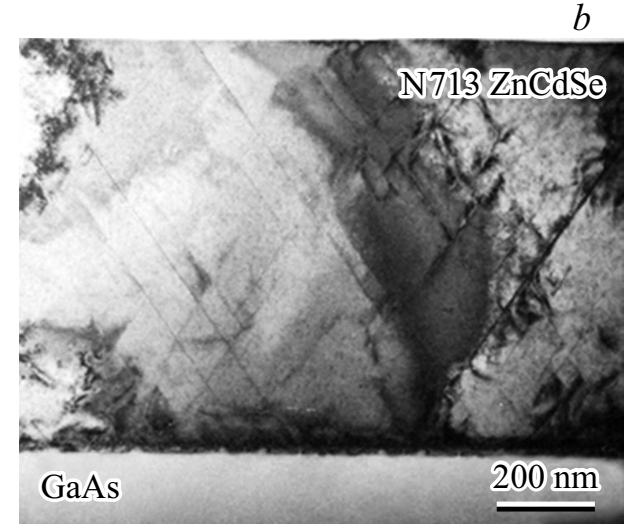

$b$

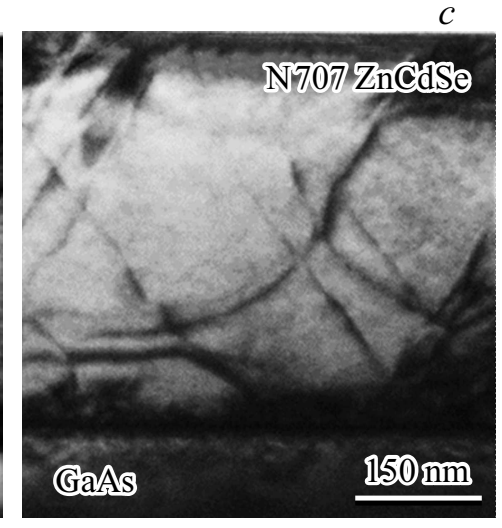

e
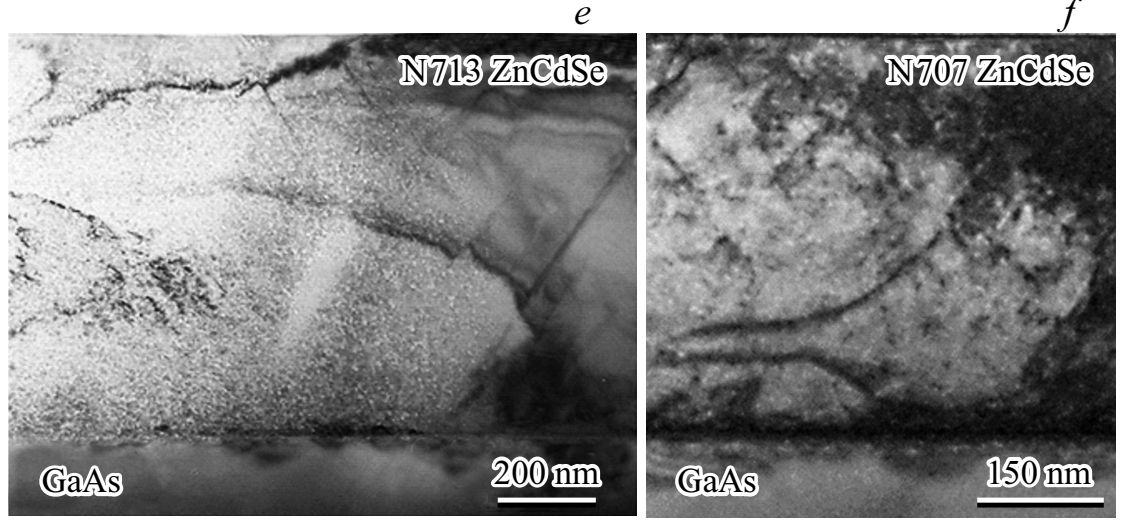

Рис. 2. ПЭМ-изображения до облучения образцов: $a)$ - №688, $b)$ - № 713, c) - № 707; ПЭМ-изображения образцов после облучения электронным пучком: $d)$ - № 688, $e)$ - № 713, $f$ ) - № 707. Изображения были получены при энергии электронного пучка $100 \mathrm{keV}$ для образцов № 688 и № 713 и $200 \mathrm{keV}$ для образца № 707, плотность тока в обоих случаях был порядка $I \sim 1$ nА. 
$a$

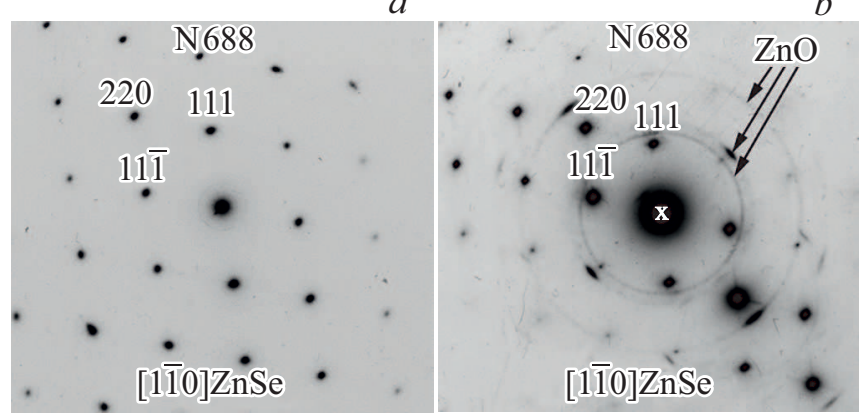

Рис. 3. $а$ ) микродифракция области образца № 688 до облучения в ПЭМ, $b$ ) микродифракция облученной области образца № 688.

Таким образом, облучение образцов в условиях высокой плотности мощности электронного пучка с энергиями 100 и $200 \mathrm{keV}$ привело к уменьшению количества дефектов упаковки в эпитаксиальных слоях. При этом данный процесс сопровождается образованием пор и гексагональных преципитатов оксида цинка в исследуемых слоях.

\section{3. Облучение электронным пучком с энергией $10 \mathrm{kev}$}

На рис. 4 представлены спектры КЛ всех образцов, полученные во время облучения при больших токах электронного пучка $I=100 \mathrm{nA}$. В ходе облучения при комнатной температуре во всех образцах значительно уменьшается интенсивность КЛ. Также стоит отметить, что состав образцов в процессе облучения не изменялся при точности определения $\pm 1 \%$ rel., т. е. испарение Se не наблюдалось.

Уменьшение интенсивности КЛ может быть связано как с процессом деградации пленок, так и с нарастанием контаминационной углеводородной пленки, подробно исследованной в работе [12]. Методом атомно-силовой микроскопии была измерена толщина контаминационной пленки, образовавшейся на образце после $20 \mathrm{~min}$ облучения электронным пучком. Средняя толщина ее составила величину $\sim 50 \mathrm{~nm}$. Согласно работе [13] пленка такой толщины имеет поглощение интенсивности излучения $\sim 30 \%$ при $2.7 \mathrm{eV}, \sim 20 \%$ при $2.25 \mathrm{eV}$, и $\sim 10 \%$ интенсивности при $1.84 \mathrm{eV}$. В нашем случае это означает, что поглощение в области краевых полос не превышает 30\% общей интенсивности, а поглощение в области широких полос не больше 10\%. Поэтому, можно предположить, что наблюдаемое уменьшение интенсивности КЛ связано не только с образованием контаминационной пленки.

Как видно на рис. 4, наблюдается существенное изменение формы широкой полосы при облучении образца № 713 при комнатной температуре. В ходе облучения электронным пучком в спектре КЛ образца №713 дуплет с двумя максимумами преобразуется в одну широкую полосу с максимумом в $1.85 \mathrm{eV}$ (рис. 5). Для образца № 713 были получены спектры отражения, в последствие пересчитанные в спектры поглощения (рис. 5).
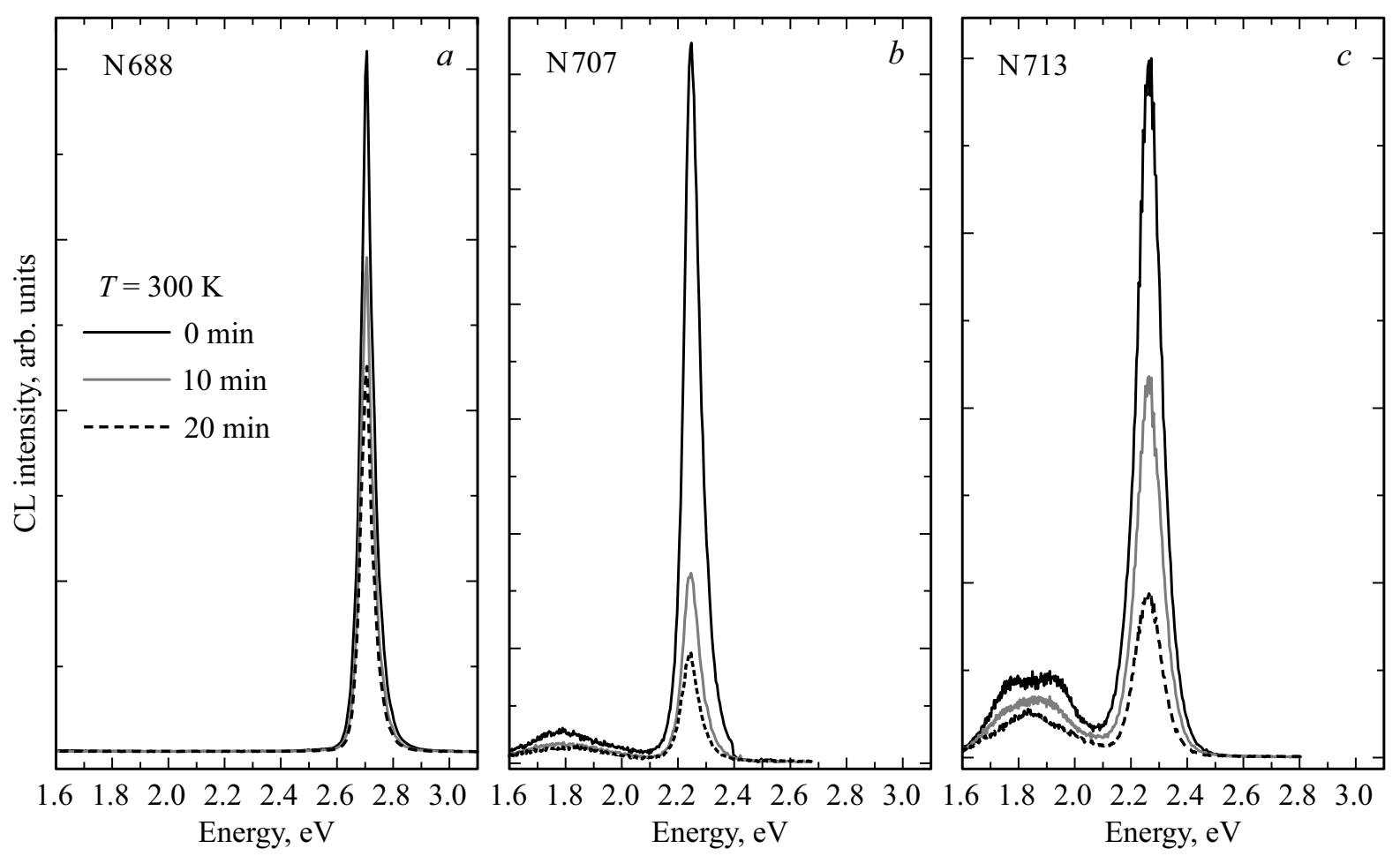

Рис. 4. Спектры КЛ, полученные в процессе облучения электронным пучком образцов $a$ ) ZnSe № 688 , $b$ ) ZnCdSe № 707 и c) ZnCdSe № 713 при температуре $T=300 \mathrm{~K}$. На рисунке указано время облучения образца $(0,10,20 \mathrm{~min})$. 


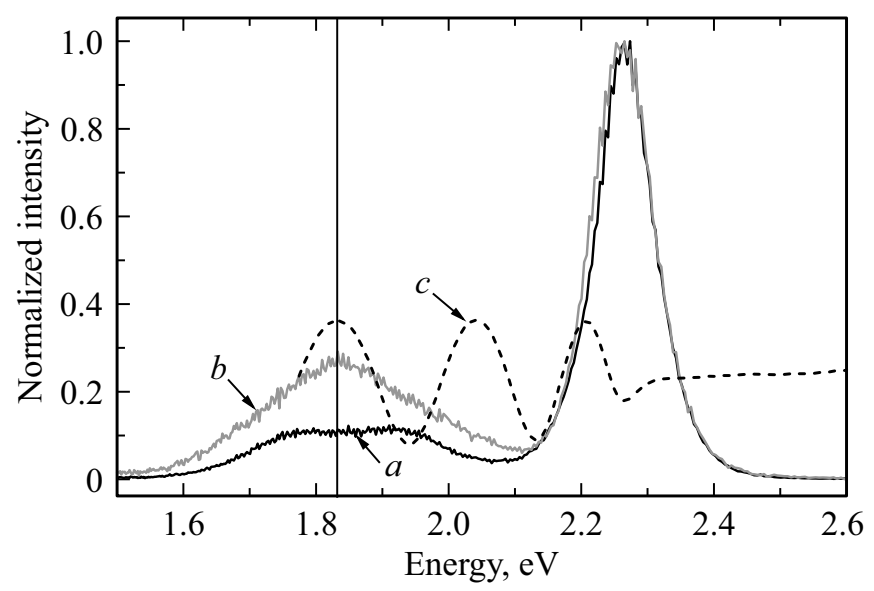

Рис. 5. $a$ ) спектр КЛ-образца № 713 без предварительного облучения, $b$ ) спектр КЛ-образца № 713 после 20 min облучения и $c$ ) спектр поглощения образца № 713 .

В спектре наблюдались интерференционные осцилляции характерные для пленки $\mathrm{Zn}_{0.68} \mathrm{Cd}_{0.32} \mathrm{Se}$ толщиной $1 \mathrm{mkm}$. На рис. 5 видно, что максимум широкой полосы образца № 713 в спектре КЛ и один из пиков поглощения в области $1.85 \mathrm{eV}$ совпадают. Поэтому изменение формы широкой полосы в спектрах вероятно связанно с нивелированием интерференционного поглощения в результате облучения электронным пучком.
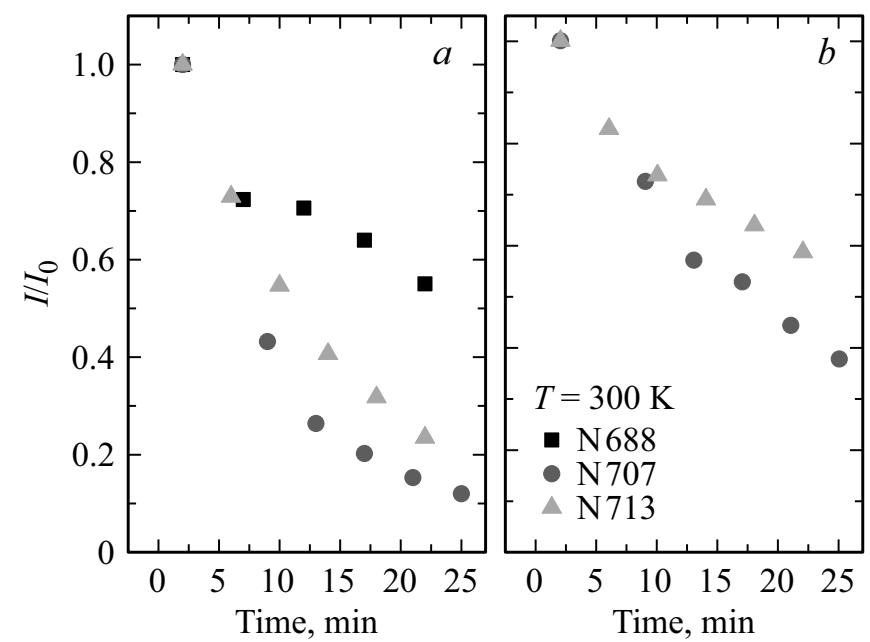

Рис. 6. Зависимости интенсивности полос КЛ от времени облучения электронным пучком при температуре $T=300 \mathrm{~K}$. a) изменение интенсивности люминесценции краевой полосы, $b)$ изменение интенсивности люминесценции широкой полосы. На рисунке указан номер образца.

На рис. 6 приведены зависимости интенсивности полос КЛ от времени облучения электронным пучком.

На рис. 6, $а$ продемонстрировано, что при КЛ исследованиях за 20 min облучения электронным пучком интенсивность излучения краевых полос уменьшается

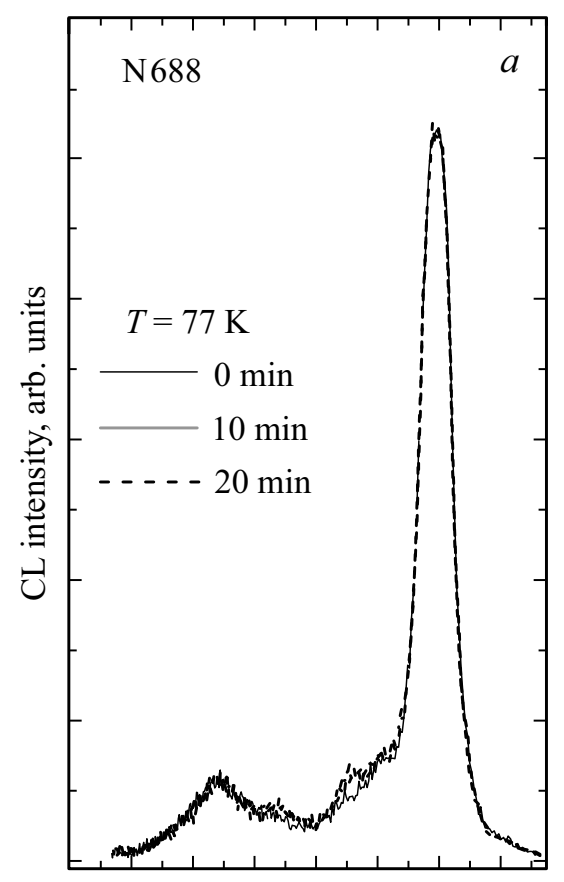

$\begin{array}{lllllllll}1.6 & 1.8 & 2.0 & 2.2 & 2.4 & 2.6 & 2.8 & 3.0\end{array}$ Energy, eV

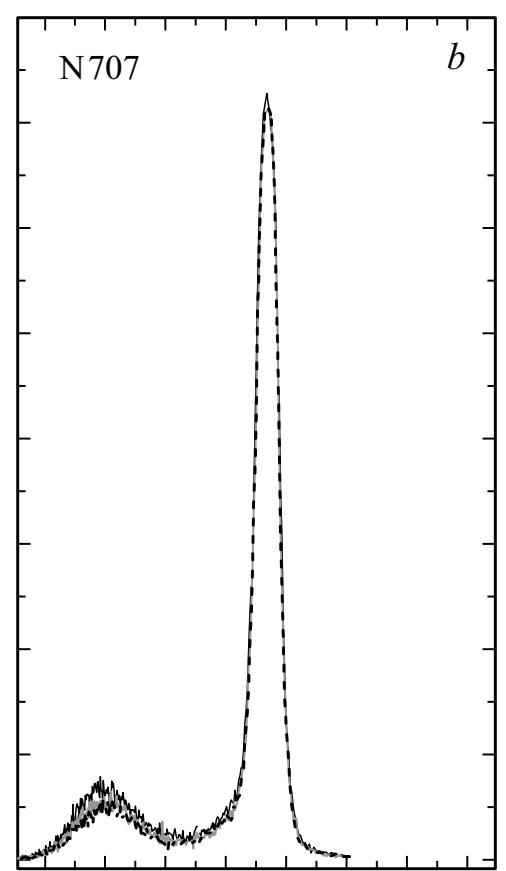

$\begin{array}{lllllllllll}1.6 & 1.8 & 2.0 & 2.2 & 2.4 & 2.6 & 2.8 & 3.0\end{array}$ Energy, eV

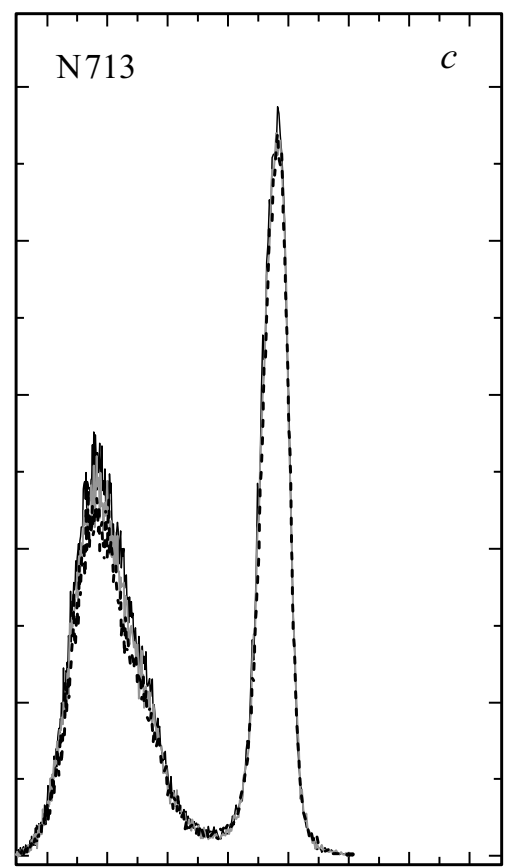

$\begin{array}{lllllllll}1.6 & 1.8 & 2.0 & 2.2 & 2.4 & 2.6 & 2.8 & 3.0\end{array}$ Energy, eV

Рис. 7. Спектры КЛ, полученные в процессе облучения электронным пучком образца $a$ ) ZnSe № 688 , b) ZnCdSe № 713 и c) $\mathrm{ZnCdSe}$ № 707 при температуре $77 \mathrm{~K}$. На рисунке указано время облучения образца перед началом регистрации соответствующего спектра. 
Таблица 2. Время затухания широких полос до и после облучения электронным пучком

\begin{tabular}{c|c|c}
\hline \multicolumn{2}{c|}{ Образец } & $\begin{array}{c}\text { Время затухания } \\
\text { широкой полосы, mks }\end{array}$ \\
\hline \multirow{2}{*}{ № 713 } & до облучения & 3.6 \\
\cline { 2 - 3 } & после облучения & 4.1 \\
\hline \multirow{2}{*}{ № 707 } & до облучения & 3.3 \\
\cline { 2 - 3 } & после облучения & 4.3
\end{tabular}

более чем на $50 \%$ для всех образцов. Интенсивность КЛ широких полос (рис. 6, $b$ ) падает медленнее, чем интенсивность краевых полос. Для определения природы процесса падения интенсивности КЛ широких полос было измерено изменение их интенсивности КЛ от времени (время затухания) до и после облучения электронным пучком (табл. 2).

Для определения влияния температуры на процессы дефектообразования было проведено облучение электронным пучком с одновременной регистрацией КЛ спектров так же при температуре $77 \mathrm{~K}$, представленные на рис. 7. В спектрах КЛ всех образцов, полученных при $77 \mathrm{~K}$, наблюдался температурный сдвиг краевой полосы на $0.8 \mathrm{eV}$, относительно положения полосы при $T=300 \mathrm{~K}$, связанный с известным для полупроводников эффектом - увеличением ширины запрещенной зоны при охлаждении образцов, что согласуется с литературными данными [16]. Отношение интенсивности широкой полосы к интенсивности краевой полосы при $77 \mathrm{~K}$ увеличилось во всех образцах. Также при $77 \mathrm{~K}$ проявляется широкая полоса в спектре образца № 688 . Облучение проводилось при тех же параметрах электронного пучка, что и в эксперименте при комнатной температуре. При этом следует отметить, что форма и интенсивность спектров КЛ всех образцов не изменились при облучении в течение $20 \mathrm{~min}$. Отсутствие изменений в спектрах при температуре $77 \mathrm{~K}$ можно объяснить тем, что вероятность образования дефектов вследствие облучения уменьшается при уменьшении температуры [17].

\section{4. Обсуждение результатов. Процессы, происходящие в образцах под воздействием электронного пучка}

Деградация образца при облучении электронным пучком может происходить вследствие радиационно-стимулированных процессов или в результате локального нагрева образца из-за торможения электронов в материале [1]. Эти два механизма деградации стоит рассмотреть отдельно.

\section{1. Локальный нагрев образца электронным пучком}

Для сравнения локального радиационного нагрева при исследовании методами ПЭМ и КЛ была проведена теоретическая оценка температуры нагрева облучаемого микрообъема $\mathrm{ZnSe}$. Оценка производилась для максимально используемых токов электронного пучка при облучении. При расчете температуры нагрева предполагалось, что $100 \%$ потерянной в образце энергии электронного пучка преобразовывается в тепло. Такое предположение позволяет вычислить максимально возможную температуру локального радиационного нагрева.

При облучении в КЛ-установке (длина проникновения электронов в образец меньше, чем толщина исследуемого образца) форма области генерации тепла аппроксимировалась полуэллипсоидом (рис. 8, $a$ ), где полуосями выступали радиус электронного пучка $b$ и глубина проникновения электронного пучка в образец - $a$. Глубина проникновения электронного пучка моделировалась в программном пакете Casino v.2.4.8.1. При ускоряющем напряжении электронного пучка $10 \mathrm{keV}$, глубина проникновения в $\mathrm{ZnSe}$ составляет $\sim 400 \mathrm{~nm}$.

Согласно [18], максимальная температура нагрева микрообъема образца при генерации тепла в сплюснутом эллипсоиде вращения $(a<b)$ может быть оценена по формуле

$$
T_{\max }=\frac{q_{0}(a, b)}{2 k} \frac{a b^{2}}{\sqrt{\left(b^{2}-a^{2}\right)}} \operatorname{arct}\left(\frac{a}{\sqrt{\left(b^{2}-a^{2}\right)}}\right),
$$

где $q_{0}(a, b)$ - потерянная энергия в единице объема образца и $k-$ коэффициент теплопроводности $\mathrm{ZnSe}, b-$ радиус электронного пучка, $a-$ глубина проникновения электронного пучка в образец.

При облучении в ПЭМ (длина проникновения электронов в образец существенно больше, чем толщина исследуемого слоя) форма области генерации тепла аппроксимировалась цилиндром (рис. $8, b$ ) с радиусом равным радиусу электронного пучка $b$. Высотой цилиндра выступала средняя толщина утоненного образца $a$ $(100 \mathrm{~nm})$. Доля потерянной энергии в слое $\mathrm{ZnSe}$ толщиной в $100 \mathrm{~nm}$ моделировалась в программном пакете Casino v.2.4.8.1.

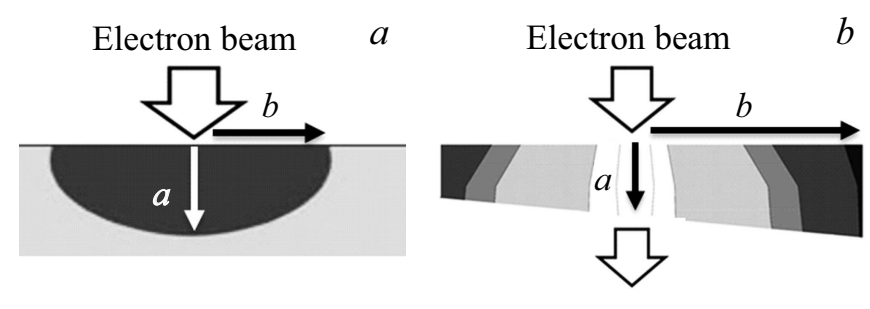

Рис. 8. Область взаимодействия электронного пучка с объемным образцом в КЛ $(a)$ установке и с утоненным образцом в ПЭМ-установке $(b)$. Где $a-$ глубина проникновения электронного пучка в образец, $b-$ радиус электронного пучка. 
Таблица 3. Рассчитанная температура нагрева ZnSe при различных режимах облучения

\begin{tabular}{l|c|c|c}
\hline \multicolumn{1}{c|}{ Метод исследования } & КЛ & ПЭМ & ПЭМ \\
\hline Энергия электронного пучка $E, \mathrm{keV}$ & 10 & 100 & 200 \\
\hline Поглощенный ток I, nA & 100 & 100 & 25 \\
\hline Радиус электронного пучка $b, \mathrm{mkm}$ & 2 & 1 & 1 \\
\hline $\begin{array}{l}\text { Глубина проникновения } \\
\text { электронного пучка в образец } a, \mathrm{~nm}\end{array}$ & 400 & 100 & 100 \\
\hline$T_{\max }, \mathrm{K}$ & 5 & 26 & 5
\end{tabular}

В этом случае температура нагрева микрообъема образца рассчитывается по формуле [19]:

$$
T_{\max }=\frac{q_{0}(a, b)}{4 k} b^{2},
$$

где $q_{0}(a, b)$ - потерянная энергия в единице объема образца и $k-$ коэффициент теплопроводности $\mathrm{ZnSe}$, $b-$ радиус электронного пучка.

Результаты расчетов температуры нагрева и условия облучения приведены в табл. 3.

В случае тройного соединения ZnCdSe с кубической структурой теоретические расчеты температуры нагрева затруднены, поскольку в литературе не приведено экспериментальных значений теплопроводности данного соединения. Из литературных данных известно, что из-за разупорядочения системы теплопроводность трехкомпонентных соединений $A_{x} B_{1-x} C$, как правило, в несколько раз меньше, чем теплопроводность двухкомпонентных соединений $A C$ или $B C$ [20]. Таким образом, нагрев пленок $\mathrm{ZnCdSe}$ может быть в несколько раз больше, чем у $\mathrm{ZnSe}$ при тех же условиях облучения. Соответственно, температура нагрева ZnCdSe не должна превышать $200^{\circ} \mathrm{C}$ при облучении в ПЭМ установке и не более $50^{\circ} \mathrm{C}$ при облучении в КЛ установке. Данной величины нагрева недостаточно для изменения структуры материала, так как соединения на основе $\mathrm{ZnSe}$ и $\mathrm{ZnCdSe}$ обладают термической стабильностью вплоть до $400-600^{\circ} \mathrm{C}[21,22]$.

Таким образом, локальный нагрев образцов электронным пучком не может объяснить все наблюдаемые в данной работе эффекты.

\section{2. Радиационное воздействие при упругом и неупругом взаимодействии электронного пучка с образцом}

Рассмотрим вопрос радиационных повреждений при упругом рассеянии электронов на атомах материала. Образование радиационных дефектов - френкелевских пар в идеальной кристаллической решетке под воздействием электронного пучка, как правило, имеет пороговый характер. Энергия образования френкелевской пары в кристалле $\mathrm{ZnSe}$ составляет $7.6 \mathrm{eV}$ для катионной подрешетки $(\mathrm{Zn})$ и $8.2 \mathrm{eV}$ для анионной подрешетки (Se) [1]. Максимальная энергия, которая может быть передана от электрона атому вещества при упругом рассеянии определяется формулой

$$
E_{\max }=\frac{2 E^{1}\left(E^{1}+2 m_{0} c^{2}\right)}{M c^{2}},
$$

где $E^{1}-$ энергия первичного электронного пучка, $m_{0}$ - масса электрона, $M$ - масса атома на котором рассеивается электрон, $c$ - скорость света.

Рассчитанная по формуле (1), энергия электрона необходимая для смещения атома $\mathrm{Zn}$ в междоузлие должна превышать $190 \mathrm{keV}$, а для смещения атома $\mathrm{Se}$ в междоузлие энергия электрона должна превышать $240 \mathrm{keV}$. Стоит отметить, что наличие в кристалле дефектов может приводить к уменьшению энергии образования радиационных дефектов.

Поскольку кадмий имеет достаточно большую атомную массу, его участием в процессе дефектообразования при упругом взаимодействии электронного пучка с образцом можно пренебречь.

При неупругом взаимодействии электронного пучка с образцом радиационные повреждения полупроводникового материала возникают вследствие ионизации атома электронами [23]. В момент ионизации атома вероятность перехода данного атома в междоузлие под воздействием тепловых колебаний из узла кристаллической решетки значительно возрастает, вследствие ослабления обменных связей и снижения потенциального барьера. В работе [23] утверждается, что радиационные нарушения в полупроводниковых материалах вследствие ионизации атомов могут происходить при воздействии электронного пучка с энергией в единицы $\mathrm{keV}$ и более.

Таким образом в случае облучения электронным пучком в ПЭМ-установке при энергии $200 \mathrm{keV}$ должны наблюдаться радиационные повреждения связанные как с упругим, так и с не упругим рассеянием электронного пучка на атомах образца, а в случае облучения электронным пучком в КЛ-установке при энергии $10 \mathrm{keV}$ наиболее вероятно будут превалировать радиационные повреждения наблюдаемые при неупругом взаимодействии электронного пучка с полупроводниковым материалом.

\section{5. Обсуждение результатов облучения электронным пучком с энергией 100 и 200 kev в ПЭМ-установке}

В результате облучения происходит образование радиационных дефектов в катионной подрешетке $(\mathrm{Zn})$. Следствием этого является образование пор и преципитатов $\mathrm{ZnO}$ в облученном материале.

Образование пор, вероятнее всего, происходит за счет миграции и скопления вакансий цинка [1]. Образование гексагональных преципитатов $\mathrm{ZnO}$ происходит в результате взаимодействия междоузельного цинка с 
кислородом. Присутствие кислорода в образцах, вероятно, связано с процессом пробоподготовки (утонение образцов методом ионного травления проводится на воздухе).

Процессы, происходящие при облучении образцов электронным пучком с энергией $100 \mathrm{keV}$ и $200 \mathrm{keV}$, качественно не отличаются. Хотя энергии $100 \mathrm{keV}$ недостаточно для образования радиационных дефектов в кристаллической решетке $\mathrm{ZnSe}$ при упругом взаимодействии электронного пучка с образцом, данный факт может быть объяснен наличием дефектов, образовавшихся в процессе роста. Это приводит к искажению кристаллической решетки и уменьшению энергии образования радиационных дефектов, что делает энергию облучения в $100 \mathrm{keV}$ также достаточной для образования наблюдаемых структурных изменений.

\section{6. Осуждение результатов облучения электронным пучком с энергией $10 \mathrm{kev}$ в КЛ-установке}

Изменение катодолюминесцентных характеристик (уменьшение интенсивности катодолюминесценции, увеличение времен затухания широких полос) происходит при облучении электронным пучком с энергией $10 \mathrm{keV}$ только при комнатной температуре. Отсутствие изменений в спектрах при температуре $77 \mathrm{~K}$ можно объяснить тем, что вероятность образования радиационных дефектов уменьшается при уменьшении температуры. Так как, вероятность перехода атомов из узла кристаллической решетки материала в междоузлие под воздействием тепловых колебаний, напрямую зависит от температуры [12].

Наблюдаемое уменьшение интенсивности краевой люминесценции при комнатной температуре (рис. 6, $a$ ) можно связать с возникновением точечных дефектов или их конгломератов, которые являются центрами безызлучательной рекомбинации [14]. Это подтверждается тем, что, наиболее быстрый спад интенсивности наблюдается в образцах с изначально большим количеством дефектов упаковки, влияющих на скорость дефектообразования при облучении электронным пучком.

Интенсивность широких полос, ассоциированных с вакансиями цинка, падает медленнее, чем интенсивность краевых полос (рис. 6, $b$ ). Уменьшение интенсивности этих полос может быть объяснено, как уменьшением концентрации центров люминесценции, так и образованием дополнительных центров безызлучательной рекомбинации. Для определения природы этого процесса были измерены времена затухания широких полос излучения до и после облучения электронным пучком (табл. 2). Увеличение времени послесвечения в результате облучения образцов электронным пучком говорит об уменьшении количества собственных дефектов, являющихся центрами люминесценции. По методике, описанной в работе [11], было рассчитано изменение концентрации этих центров люминесценции. Соотношение содержания центров люминесценции можно определить следующим образом:

$$
\frac{N_{1}}{N_{2}}=\frac{I_{1 \tau_{1}^{-1}}}{I_{2 \tau_{2}^{-1}}},
$$

где $N$ - содержание люминесцентных центров, $I-$ интенсивность люминесценции, $\tau-$ время затухания соответствующей полосы.

Расчет показал, что после облучения концентрация излучающих центров существенно уменьшается: в образце № 707 в 2.6 раза, в образце № 713 в 1.7 раза. Уменьшение концентрации центров люминесценции свидетельствует о радиационно-стимулированном отжиге или трансформации люминесцентных центров в дефекты, что приводит к уменьшению интенсивности люминесценции широкой полосы. Подобный расчет не был выполнен для образца № 688, так как у этого образца не наблюдалось широкой полосы при комнатной температуре. Возможно облучение электронным пучком приводит к образованию конгломератов вакансий цинка, что приводит изменению их энергетического положения внутри зоны и, соответственно, к уменьшению концентрации люминесцентных центров.

Таким образом, уменьшение интенсивности полосы краевой люминесценции происходит за счет появления центров безызлучательной рекомбинации. А уменьшение интенсивности широких полос может быть объяснено уменьшением концентрации (трансформацией или отжигом) центров люминесценции.

\section{7. Заключение}

При облучении образцов в просвечивающем электронном микроскопе наблюдался отжиг дефектов упаковки, образование преципитатов $\mathrm{ZnO}$ с гексагональной кристаллической структурой и возникновение пор. Образование преципитатов $\mathrm{ZnO}$ и пор связано с обширным образованием вакансий цинка. Испарения или кластеризации селена зафиксировано не было. Показано, что процессы, происходящие при облучении образцов электронным пучком с энергией 100 и $200 \mathrm{keV}$, качественно не отличаются.

При исследовании влияния облучения на люминесцентные свойства структур было показано, что процессы уменьшения интенсивности КЛ наблюдаются только при комнатной температуре и являются необратимыми. Уменьшение интенсивности КЛ полос в спектрах происходит вследствие радиационно-стимулированных процессов дефектообразования. Уменьшение интенсивности полосы краевой люминесценции происходит из-за образования центров безызлучательной рекомбинации и увеличения доли безызлучательной переходов. Уменьшение интенсивности широкой полосы связано с уменьшением содержания центров люминесценции, ассоциированных с вакансиями цинка. Возможно, наблюдается процесс трансформации или отжига люминесцентных центров. 


\section{Финансирование работы}

Исследования методом ПЭМ выполнены с использованием оборудования федерального ЦКП „Материаловедение и диагностика в передовых технологиях“ и поддержаны Минобрнауки России (Уникальный идентификатор проекта RFMEFI62119X0021).

\section{Конфликт интересов}

Авторы заявляют об отсутствии конфликта интересов.

\section{Список литературы}

[1] Ю.Ю. Логинов, Пол Д. Браун, Кен Дьюроуз. Закономерности образования структурных дефектов в полупроводниках $\mathrm{A}^{2} \mathrm{~B}^{6}$. Логос, М. (2003). 304 c.

[2] S. Gundel, D. Albert, J. Nurnberger, W. Faschinger. Phys. Rev. B 60, R16271 (1999).

[3] S.V. Sorokin, I.V. Sedova, S.V. Gronin, G.V. Klimko, K.G. Belyaev, S.V. Ivanov, A. Alyamani, E.V. Lutsenko, A.G. Vainilovich, G.P. Yablonskii. Electron. Lett. 48, 2, 118 (2012).

[4] A.G. Vainilovich, E.V. Lutsenko, V.N. Pavlovskii, G.P. Yablonskii, A. Alyamani, M. Aljohenii, A. Aljerwii, S.V. Gronin, S.V. Sorokin, I.V. Sedova, S.V. Ivanov. Phys. Status Solidi B 253, 8, 1498(2016).

[5] M.M. Zverev, S.V. Sorokin, N.A. Gamov, E.V. Zhdanova, V.B. Studionov, I.V. Sedova, S.V. Gronin, S.V. Ivanov. Phys. Status Solidi C 13, 7-9, 661 (2016).

[6] М.М. Зверев, Н.А. Гамов, Е.В. Жданова, Д.В. Перегудов, В.Б. Студенов, С.В. Иванов, И.В. Седова, С.В. Сорокин, С.В. Гронин, П.С. Копьев. Письма в ЖТФ 33, 24, 1 (2007).

[7] M.M. Zverev, N.A. Gamov, E.V. Zdanova, V.N. Studionov, D.V. Peregoudov, S.V. Sorokin, I.V. Sedova, S.V. Gronin, P.S. Kop'ev, I.M. Olikhov, S.V. Ivanov. Phys. Status Solidi B 247, 6, 1561 (2010).

[8] М.М. Зверев, Н.А. Гамов, Е.В. Жданова, Д.В. Перегудов, В.Б. Студенов, С.В. Гронин, И.В. Седова, С.В. Сорокин, С.В. Иванов. Поверхность 1, 27 (2013).

[9] M.V. Zamoryanskaya, S.G. Konnikov, A.N. Zamoryanskii Instrum. Exp. Tech. 4, 477 (2004).

[10] L.V. Borkovska, N.O. Korsunska, V.I. Kushnirenco. Semicond. Phys. 6, 3, 294 (2003).

[11] K.M. Lee, D. Le Si, G.D. Watkins. Solid State Commun. 35, 7, 527(1980).

[12] К.Н. Орехова, Ю.М. Серов, П.А. Дементьев, Е.В. Иванова, В.А. Кравец, В.П. Усачева, М.В. Заморянская. ЖТФ 89, 9, 1412 (2009).

[13] A.Yu. Mester, A.N. Trofimov, M.V. Zamoryanskaya, A.M. D’yakonov. Tech. Phys. 59, 10, 1536 (2014).

[14] Х. Кейси, М. Паниш. Лазеры на гетероструктурах. Мир, M. (1981). T. 2. 358 c.

[15] Е.В. Иванова, М.В. Заморянская. ФТТ 58, 1895 (2016).

[16] A.A. Shakhmin, I.V. Sedova, S.V. Sorokin, H.-J. Fitting, M.V. Zamoryanskaya. Physica B: Condens. Matter 404, 23-24, 5016 (2009).
[17] Б.И. Болтакс. Диффузия и точечные дефекты в полупроводниках. Наука, Л. (1972). 384 с.

[18] Л.А. Бакалейников, Е.В. Галактионов, В.В. Третьяков, Э.А. Тропп. ФТТ 43, 5, 779 (2001).

[19] М.В. Заморянская, Е.В. Иванова, А.А. Ситникова. ФТТ 53, 7, 1399 (2011).

[20] Г.Н. Дульнев, Ю.П. Заричняк. Теплопроводность смесей и композиционных материалов. Энергия, Л. (1974). 264 с.

[21] T. Yokogawa, P.D. Floyd, J.L. Merz, H. Luo, J.K. Furdyna. J. Cryst. Growth 138, 564 (1994).

[22] T. Yokogawa, J.L. Merz, H. Luo, J.K. Furdyna, S. Lau, M. Kuttler, D. Bimberg. Jpn. J. Appl. Phys. 34, 1159 (1995).

[23] В.С. Вавилов, А.Е. Кив, О.Р. Ниязова. Механизмы образования и миграции дефектов в полупроводниках. Наука, М. (1981).

Редактор К.В. Емщев 